\title{
AdolescênCIAS, AUTONOMIA E DIREITOS SEXUAIS: FRAGMENTOS DE HISTÓRIAS DE MENINAS ABRIGADAS
}

\author{
Anna Paula Uziel* \\ Felix Augusto Jacobson Berzins**
}

\section{Resumo}

A relação entre autonomia, adolescência e direitos sexuais levanta questóes importantes para o cotidiano de instituiçóes de acolhimento institucional. Adolescentes abrigadas que possuem vida sexual ativa nos interpelam sobre nossos valores morais no campo da sexualidade. Este artigo discute perspectivas de sexualidade e de exercício dos direitos sexuais entre meninas adolescentes em situação de acolhimento institucional a partir da noção de autonomia, desenvolvida nas instituiçóes do Estado como estratégia de proteção.

Palavras-chave: adolescência; autonomia; direitos sexuais.

\begin{abstract}
ADOLESCENCE, AUTONOMY AND SEXUAL RIGHTS: FRAGMENTS OF STORIES OF GIRLS LIVING IN SHELTERS

The relationship between autonomy, adolescence and sexual rights raises important issues for daily residential care institutions. Sexually active adolescents who have been sheltered challenge us about our moral values regarding sexuality. This article discusses prospects for the exercise of sexuality and sexual rights among adolescent girls in situations of host institution, based on the notion of autonomy developed in state institutions as a strategy for protection

Keywords: adolescence; autonomy; sexual rights.
\end{abstract}

* Instituto de Psicologia, UERJ, Rio de Janeiro, RJ, Brasil. Email: uzielap@gmail.com.

** Instituto de Psicologia, UERJ, Rio de Janeiro, RJ, Brasil. E-mail: felixberzins@gmail.com. 


\section{Introdução}

Adolescência e sexualidade são dois temas que, cada vez mais, se entrelaçam. Com o início da vida sexual acontecendo mais cedo, esta fase acaba sendo de experimentação. No Brasil, o aumento do número de gravidezes entre as adolescentes tem feito com que a temática da sexualidade, associada à reprodução, entre em pauta. Em geral, o debate tem um tom normativo, com intuito de diminuir o número de filhos das jovens nessa faixa etária - que já vem decrescendo desde 2007. Embora o aborto seja permitido no Brasil somente nos casos de estupro e em que a mãe corre risco de vida, sabe-se, sem estatísticas ou maiores dados, que as camadas médias recorrem a clínicas ilegais para interrupçáo da gravidez. $\mathrm{O}$ mesmo náo pode ser feito pelas adolescentes pobres que, quando se submetem a esse procedimento realizado de maneira precária, correm sérios riscos de vida. Em função desta e de outras razões, o número de filhos de adolescentes de camadas populares é maior. Mais um aspecto da desigualdade social em nosso país.

Os movimentos feministas conquistaram nos anos 1960, com a pílula anticoncepcional, uma eficaz dissociação entre sexo e reprodução. A partir daquele momento foi possível abordar o prazer feminino, a opção por ter filhos mais tarde ou simplesmente não tê-los, entre outras possibilidades reorganizadas com o avanço das tecnologias reprodutivas, como a estabilidade da mulher no mercado de trabalho, a crise da masculinidade e outros fenômenos sociais.

Nos anos 1990, com todos esses ganhos, começou-se a falar em direitos sexuais, expressão que ganhou, em 1995, o texto da IV Conferência Mundial sobre a Mulher, em Beijing. No entanto, esse debate é mais tímido quando se trata de adolescentes. A necessidade de regulaçáo da fertilidade das adolescentes pobres, muito marcada no discurso dominante por uma espécie de prevenção à criminalidade, toma conta do debate.

Assim, o tema dos direitos sexuais associados a crianças e adolescentes é novo, corajoso, polêmico e desperta, necessariamente, eu arriscaria dizer, paixóes. Difícil tratar do tema sem grandes envolvimentos, sem posicionamentos claros, sem ser militante: dos direitos humanos, dos direitos sexuais e reprodutivos, das crianças e adolescentes como sujeitos de direitos.

Este artigo é inspirado por uma experiência de trabalho com adolescentes em acolhimento numa instituição do Rio de Janeiro no período de 2007 e 2008. 


\section{Metodologia}

Durante cinco anos desenvolvemos nosso trabalho em um estabelecimento de acolhimento institucional. Neste período, foram realizadas 11 entrevistas ${ }^{1}$ com adolescentes mães sobre suas trajetórias em relação a trabalho, sexualidade e parentalidade, bem como um grupo reflexivo semanal durante dois anos com essas meninas, cujas principais temáticas eram sexualidade e autonomia.

Este artigo procura refletir sobre direitos sexuais, adolescência e autonomia, baseado nesse trabalho desenvolvido, utilizando relatos de diários de campo e anotaçóes dos grupos, bem como informaçóes advindas das entrevistas individuais realizadas com as meninas, ainda que estas náo apareçam diretamente no artigo. À época foi assinado, pela direção da instituição, um termo de consentimento livre e esclarecido, visto se tratar de seu representante legal, e as meninas só concediam entrevista se estivessem de acordo; esse desejo foi sempre respeitado.

\section{Resultados: conhecendo fragmentos de suas histórias}

Vamos começar com um trecho de diário de campo de uma situação emblemática, mais comum do que podemos imaginar e que nos fez refletir muito à época e ainda demanda mais debate. Situação complexa que nos convoca a pensar a partir do ponto de vista das meninas, das crianças e da instituição.

Tinham tempos diferentes de abrigamento, todas quase na porta de saída, beirando os 18 anos, com filhos que variavam de 8 meses a 3 anos. As tardes de sábado eram livres e elas podiam sair com os filhos, desde que chegassem ao final da tarde. Uma delas, Inácia ${ }^{2}$ a que "conta tudo", como definia uma assistente social, contou sobre os encontros. Vitória, que não gostava muito de sexo com homens, ficava na sala de espera brincando com as crianças, comendo e dando doces para elas. As outras duas entravam e o advogado em geral levava um amigo. Eram práticas sexuais variadas, nem sempre penetração vaginal ou anal, muita coisa podia ser negociada. Além dos doces e do dinheiro, que era acertado desde o início e entregue à risca, era comum ganharem presentes: lingerie, roupas, bolsas, coisas para as crianças. Quando soubemos desse programa, alguns encontros já tinham acontecido. Embora soubessem que seu conteúdo não agradaria a equipe técnica da instituição, contaram 
e admitiram com certa naturalidade. Não significava que não soubessem que seus atos seriam condenados, mas não viam problema no que faziam, afinal de contas não eram obrigadas, não viam violência e não se sentiam em risco. Quando colocada na parede, Vitória se assustou com o nome de prostituição que a assistente social deu ao que faziam todos os sábados. Ela nunca tinha visto daquela forma e isso, sim, para ela era grave (Trecho do Diário de campo).

Mais dois relatos para pautar nossa discussão: um primeiro, resumo de uma das entrevistas, e o segundo, fragmento de diário de campo.

Uns meses antes de Priscila completar 18 anos, soube que seria contratada pelo abrigo ${ }^{3}$. Ela vinha com excelente desempenho na sua função com as crianças, ainda como aprendiz, e levava jeito para o trabalho. Sua avaliação positiva era unânime. Bonita, alegre, cheia de vida, gostava de sair à noite, de se vestir bem, não gostava de repetir roupa... Precisava morar sozinha com a filha, bancar essa casa e os custos das duas. As referências familiares de Priscila eram frágeis e seu vínculo forte era com sua avó, que não tinha condiçóes financeiras de recebê-la junto com sua filha. Começou a sair com um homem casado, com o dobro da idade dela, e que pagava seu aluguel (Trecho do Diário de campo).

As meninas abrigadas da casa tinham entre 13 e 18 anos incompletos. Raros eram os casos de primeiro abrigamento. Muitas tinham trajetórias bastante comuns à populaçáo que frequenta os abrigos: casa de familiares, rua, casa de conhecidos, rua, abrigo, rua, Santos Dumont, rua, abrigo [...] e um conhecimento profundo da rede. Vida sexual ativa, história com drogas, participação no mercado de trabalho informal, gravidezes, tudo isso fazia parte das histórias daquelas meninas. No entanto, num grupo em que era tematizada a sexualidade, ao ouvir de uma adolescente suas experiências com outras meninas, uma das técnicas ficou chocada: são muito novas para experimentar esse tipo de relação, elas ainda não sabem do que gostam (Trecho do Diário de campo).

$\mathrm{O}$ que essas situaçóes têm em comum para além do fato de se tratar de experiências sexuais de adolescentes mães e pobres, marcadas de formas singulares por processos de institucionalização? O que nos é tão familiar e ao mesmo tempo tão incômodo nesses fragmentos de vida? $\mathrm{O}$ que nos dá o direito de hierarquizar, julgar e nomear as práticas sexuais e afetivas experimentadas por 
essas meninas que compartilham nosso cotidiano e podem habitar concepçóes tão diferentes?

\section{Discussão: reflexóes sobre autonomia, sexualidade e direitos sexuais}

Pesquisas apontam (IPEA, 2004) que 86,7\% dos abrigados têm família e que, apesar do Estatuto da Criança e do Adolescente (ECA), em 24,2\% dos casos o motivo que levou ao abrigamento foi a pobreza. Apesar desse perfil, ou seja, de a grande maioria de crianças e adolescentes em acolhimento institucional não ser órfã, muitos dos laços afetivos estão fragilizados. Recasamentos das mães (e eventualmente dos pais), problemas na comunidade, além de outros motivos, impedem que voltem a coabitar com sua família de origem. Boa parte desses rapazes e moças viveu pouco tempo com suas famílias e possui a trajetória que descrevemos acima, com estadas interrompidas nos abrigos, nas ruas e em casas de familiares, $o$ que torna difícil a vida com suas famílias de origem. Nesse sentido, a reintegração de adolescentes é rara e muitas vezes, quando ocorre, dura pouco tempo.

Por este motivo, um dos temas centrais no trabalho com essas crianças e, sobretudo, com adolescentes, é a questão da autonomia.

Sobre este conceito, afirma Elaine Reis Brandão:

Uma premissa fundamental é a distinção entre duas dimensões constitutivas do processo de individualização, comumente tomadas como equivalentes: a autonomia, compreendida como autodeterminação pessoal e a independência, concebida como autossuficiência econômica. Para as geraçôes jovens atuais [e essa pesquisa trata de camadas médias, mas esse aspecto é em certa medida comum], a conquista da independência se coloca cada vez mais tardia, o que não impede que a autonomia seja uma aspiração cada vez mais precoce. Nas geraçóes passadas, tal autonomia estava fortemente condicionada pela emancipação financeira e residencial no país. Hoje, os termos dependência e autonomia podem se conjugar no percurso biográfico do adolescente (Brandão \& Heilborn, 2006, p. 1422).

$\mathrm{Na}$ população abrigada a dependência financeira é em relação ao Estado e a autonomia, um projeto deste Estado que a entende como condição de saída para a vida além muros. Não temos o propósito, neste texto, de discutir a questão mais específica do acesso dos abrigados a recursos financeiros. Apenas 
de informar que, nas instituiçôes de abrigamento municipais, cresce o número de convênios com órgãos de governo e parcerias com instituiçóes privadas no sentido de tentar garantir para esses jovens, enquanto estáo sob tutela do Estado, alguma experiência profissional com ganhos financeiros - que não se comparam, por exemplo, ao montante que são capazes de conseguir trabalhando no tráfico de entorpecentes.

Porém, apesar de ser possível fazer essa distinção entre autonomia e independência financeira - e ela ter marcadores de classe social muito claros -, quando se fala em autonomia nesse contexto de abrigamento se percebe no discurso institucional uma ênfase na independência financeira e não na autonomia, que nos parece um conceito chave para pensar várias dimensóes da vida do sujeito.

Quando a autonomia é somente entendida em uma perspectiva macrossocial, há um enrijecimento e imobilização do caráter criador existente em processos de singularização. E nessa lógica os adolescentes são vistos como irresponsáveis, inconsequentes, ou seja, tachados de maneira negativa por não se encaixarem nos padróes pré-estabelecidos e totalizantes do que seria a autonomia (Uziel \& Berzins, 2008, p. 7).

Apesar de a geração de autonomia (nível molar) ser eixo central na política dos abrigos de adolescentes, no cotidiano há muitas práticas que tensionam este propósito. Inspirados em Guattari (1987), ousaríamos afirmar que só seria possível instaurar processos de singularização se houvesse uma análise micropolítica que desse conta desses dois níveis, molar e molecular (Uziel \& Berzins, 2008).

Essa tensão já é de difícil administração no cotidiano do abrigo. É forte o discurso sobre a necessidade de se individualizar o acolhimento, e talvez exatamente neste ponto esteja o engano. Individualizar está marcado pelo entendimento de que é preciso garantir os mesmos direitos para náo gerar briga e injustiça. Assim, ao mesmo tempo que se pretende olhar para cada menino e menina, não se aposta na construção de planos e projetos que respondam às diversas formas de ser e estar no mundo. Aparentemente contraditório, o projeto de planos individuais acaba gerando um olhar massificado. A aposta parece ser na individualização, não na singularização. Somos, como afirmam Guattari e Rolnik (1986/2005), agenciamentos de produção coletiva.

Não datam de hoje as críticas feitas às repercussóes da institucionalização na vida de crianças e adolescentes (Siqueira \& Dell'Aglio, 2006). Desde o ECA, a autonomia está pautada, mas isso não faz dela uma categoria de fácil manobra. A ideia básica que deve ser alimentada nos estabelecimentos de acolhimento 
institucional é criar um lugar diferenciado para que os usuários, principalmente os adolescentes que estão na rede sem grandes possibilidades de reinserção familiar, possam desenvolver certo grau de autonomia com o objetivo de conseguir dar conta de suas vidas no momento em que completarem 18 anos e forem desligados.

Nossa opção ao discutir a temática é romper com a lógica culpabilizante, segundo a qual seria possível apontar os culpados por possíveis fracassos, o que normalmente recai sobre os próprios adolescentes, suas famílias de origem ou então seus educadores. Porém também rechaçamos uma posição de impotência.

$\mathrm{O}$ conceito de autonomia, que pressupóe independência financeira como fundamento, parece perder a dimensão de processo, de construção, e passa a ser tomado como um alvo bem definido de comportamento e status para esses adolescentes. Dentro desses padróes seria possível identificar os adolescentes que possuem autonomia e os que não a possuem, e a responsabilidade por alcançar esse status acaba exclusivamente sobre o sujeito em questão.

No entanto, Reichert e Wagner (2007, p. 54) apontam que "a conquista da autonomia é um processo paulatino e diário, que se inicia desde os primórdios de nossa existência e, apesar de ser um processo particular, necessita do favorecimento do contexto social". Além de ser um processo, o desenvolvimento de autonomia subentende todo um espaço coletivo. Nesse caso, dificultando um pouco a questáo, se trata de um espaço coletivo de proteção sob tutela do Estado.

Propomos dois deslocamentos necessários para fugir de um conceito de autonomia que acabe por servir de parâmetro de modelização e disciplinarizaçáo desses adolescentes institucionalizados.

O primeiro deslocamento diz respeito à independência financeira. Independência essa que está associada diretamente ao trabalho formal. Em uma sociedade em que o desemprego estrutural está cada vez mais estabelecido (Grupo Krisis, 1999), conduzir um trabalho que associa toda a ideia de autonomia à independência financeira e ao trabalho formal é carimbar desde início a falência desse projeto. Com isso não estamos ignorando os atravessamentos financeiros que afetam todos nós, mas apenas fazendo coro a todos aqueles que problematizam e criticam a subjetividade dominante que ainda afirma o trabalho como a grande valorização do sujeito e o trabalho formal como a verdadeira natureza do homem (Monteiro, Coimbra \& Mendonça Filho, 2006) - como se a opção por um trabalho, sobretudo formal, dependesse da vontade individual.

O segundo deslocamento diz respeito à autonomia como modelo a ser alcançado. Rocha e Aguiar (1997) afirmam que 
a autonomia considerada como um estado a ser alcançado através de programas determinados de ação está referida à conquista de um reino futuro onde habita a liberdade. A liberdade está sempre situada fora das circunstâncias. Deste modo, a transformação passa a ser previsível no percurso estruturado como condição a priori. No entanto, a autonomia não é uma condição que, uma vez conquistada, nos leve ao estado de equilíbrio e bem-estar permanente. Se a entendermos como função de autonomia, como afirmam Guattari e Rolnik (1986), ela é exercício, movimento, práticas de transformação, estando referida ao presente, à realidade, às circunstâncias nas quais produzimos o cotidiano (Aguiar \& Rocha, 1997, apud Rocha \& Aguiar, 2003, p. 68).

Para Guattari e Rolnik (1986/2005), a autonomia se circunda da questão da produção de subjetividade e da capacidade dos sujeitos de singularização, de produção de uma subjetividade diferente dos modelos de subjetividade dominantes do capitalismo.

Guattari e Rolnik (1986/2005), apontam que o Estado tem um papel fundamental na produção de subjetividade. Os autores afirmam que a economia subjetiva capitalística tem algumas funções e que o Estado contribui diretamente para elas: culpabilização, segregação e infantilização. Essas funções consistem em: identificar unicamente no sujeito supostos desvios - culpabilização; através de sistemas de modelização, segregar esses sujeitos desviantes - segregação; e então submetê-los a uma relação de dependência e mediação pelo Estado - infantilização. Isto é, após estabelecer as marginalidades, cria-se uma relação onde "tudo o que se faz, pensa ou se possa vir a fazer ou pensar seja mediado pelo Estado" (Guattari \& Rolnik, 1986/2005, p. 50).

A menina abrigada é mediada pelo Estado na relação com sua família de origem, com a escola, o estágio ou o trabalho. E a sexualidade? De que maneira podemos refletir através do conceito de autonomia para pensar nas tensóes entre os níveis molar e molecular quando discutimos sexualidade?

De um lado, o reconhecimento da adolescente em seu momento de descoberta da sexualidade, como diz a música $\mathrm{O}$ xote das meninas, de Luiz Gonzaga:

Toda menina que enjoa da boneca/ É siná que o amor/ Já chegou no coração.../ Ela só quer/ Só pensa em namorar.../ De manhã cedo já tá pintada/ Só vive suspirando/ Sonhando acordada/ O pai leva ao dotô/ A filha adoentada/ Não come, nem estuda/ Não dorme, náo quer nada... 
De outro, o postulado da adolescente como um sujeito de direitos. Como conjugar esses dois vieses dessa mesma menina? Que exercícios da sexualidade conseguimos conceber como do escopo do que ela pode decidir ou escolher? Que usos do corpo pode fazer? Quais são os limites do tolerável e quem arbitra? Que escutas podemos promover para essas situaçóes? Que esforços para escapar da lógica da denúncia, garantindo a proteção da adolescente, reconhecendo o dever de tutela do Estado, mas considerando que o corpo é dela? O desafio a que nos propomos aqui é integrar a discussão sobre autonomia e exercício da sexualidade.

O início da vida sexual na nossa sociedade ocorre cada vez mais cedo, como afirmarmos anteriormente. As adolescentes muitas vezes já chegam grávidas à rede de acolhimento, muitas com doenças venéreas de difícil tratamento. Enfrentam muitas dificuldades na busca por assistência e em geral são mais uma vez negligenciadas quando chegam sem nenhum respaldo de família ou de outras instituiçóes do Estado à procura de cuidados médicos ou de acompanhamento para a gravidez. No entanto, apesar de muitas vezes a gravidez - ou mais de uma - evidenciar o início da vida sexual aos 12, 13 anos, há nos abrigos, de forma mais ou menos velada, certa exigência ou pedido que essa vida sexual ativa deva ser suspensa no período em que a menina está acolhida. Sobretudo se ela é mãe. Acredita-se que essa maternidade deva dar o norte da vida das meninas. Significa dizer que os educadores se responsabilizam pelos cuidados dos filhos, por exemplo, quando as meninas precisam sair para a escola, trabalho ou estágio. Saídas para diversão, sobretudo que possam incluir namoro e sexo, são entendidas como dispensáveis e sem sentido por parte de educadores e às vezes por membros das equipes técnicas.

Voltando às duas primeiras situaçóes que relatamos: o sexo ali envolvia dinheiro, presentes, sustento. Se já é difícil tematizar a sexualidade nessas instituiçôes reguladas pelo Estado, é mais ainda quando envolve a relação com adultos e práticas que são identificáveis como prostituição. Em uma primeira conversa com essas três meninas abrigadas cujos trechos encontram-se no início do artigo, não fazia o menor sentido para elas o termo prostituição. Veem em suas vidas inúmeras situaçóes que envolvem corpo, dinheiro, sustento, presentes, o que elas entendem como sucesso. Marcadas muitas vezes por compreensôes tradicionais de gênero - que arriscamos dizer de forma generalizada que nos constituem como sujeitos, todos -, acreditam, ainda que nem sempre expressem de forma clara, que o homem pode trabalhar e sustentar a mulher.

O que vai balizar nossa concordância com usos variados do corpo? Não é possível dizer, nesse contexto, que falta consentimento, tampouco que se trata de 
crime por ser prática sexual entre menores e adultos. Aos 17 anos, por mais que sejam menores legalmente e que estejam sob proteção do Estado, esses argumentos não trazem contribuiçóes para a discussão; ao contrário, a encerram sem que tenhamos possibilidade de discutir com essas meninas os usos de seus corpos. Elas são sujeitos de direito quando escolhem fazer sexo com pessoas em troca de prazer, de amor e, por que não, de dinheiro. Quais parâmetros podemos utilizar que contornem o moralismo de plantão para que possamos nos aproximar um pouco mais da lógica que as meninas possuem na tomada de suas decisóes? Como ir além da discussão sobre violência que certamente está presente potencialmente nesses casos, mas que pode não aparecer? A violência deve ser um elemento, não pode tomar a frente do que é central na discussão que é a autonomia para o exercício da sexualidade.

Embora a questáo da classe social esteja colocada, visto que o acesso a bens de consumo para adolescentes de camadas médias e altas, que recebem as mesmas propagandas de produtos e valores que as abrigadas, seja bem mais facilitado, o tema náo nos parece relevante simplesmente por se tratar de meninas pobres. No entanto, estamos nos referindo apenas às meninas pobres, visto que são elas que circulam nas instituiçóes do Estado e por ele têm suas vidas reguladas. Acrescenta-se ainda que a pobreza, a miséria, a falta de escolaridade e de perspectiva de futuro com um caminho de escolha estão presentes nessa discussão e são elementos importantes. No entanto, queremos propor um debate que vá além desses pontos que constatamos com mais facilidade e pesar e que, a longo prazo, dependem de mudanças estruturais na sociedade brasileira.

Enquanto isso, as meninas estâo nos abrigos e as medidas de proteção que podemos implementar exigem de nós que pautemos discussões sobre sexualidade incorporando as situaçóes que elas vivem no mundo real. O exercício da sexualidade é múltiplo e restringir sua amplitude na discussão quando se trata de adolescentes abrigadas pode significar desproteção.

Propomos reflexóes orientados por uma fala de Deleuze (2002) que diz que basta não conhecer para moralizar. Faz-se necessário um mergulho no universo de sentidos que as adolescentes dáo para suas práticas.

\section{Referências}

Brandão, E. R. \& Heilborn, M. L. (2006). Sexualidade e gravidez na adolescência entre jovens de camadas médias do Rio de Janeiro, Brasil. Cad. Saúde Pública, 22(7), 1421-1430.

Deleuze, G. (2002). Espinosa. Filosofia prática. São Paulo: Escuta. 
Grupo Krisis (1999). Manifesto contra o trabalho. São Paulo. Geousp/Lapur.

Guattari, F. (1987). Revoluçôes moleculares: pulsaçôes políticas do desejo. São Paulo: Brasiliense.

Guattari, F. \& Rolnik, S. (1986). Micropolitica: cartografias do desejo. Petrópolis: Vozes, 2005.

IPEA (2004). Levantamento nacional de abrigos para crianças e adolescentes da rede SAC.

Rio de Janeiro: IPEA. Disponível em <http://portaldovoluntario.v2v.net/documents/0000/0189/109726162757.pdf>. Recuperado em 10 de agosto de 2011.

Monteiro, A., Coimbra, C. \& Mendonça Filho, M. (2006). Estado democrático de direito e políticas públicas: estatal é necessariamente público? Psicol. Soc., 18(2), 7-12.

Reichert, C. B. \& Wagner, A. (2007). Consideraçóes sobre a autonomia na contemporaneidade. Estudos e Pesquisas em Psicologia, 7(3), 405-418.

Rocha, M. L. \& Aguiar, K. F. (2003). Pesquisa-intervenção e a produção de novas análises. Psicologia Ciência e Profissão, 23, 25-33.

Siqueira, A. C. \& Dell'Aglio, D. D. (2006). O impacto da institucionalização na infância e na adolescência: uma revisão de literatura. Psicol. Soc., 18(1), 71-80.

Uziel, A. P. \& Berzins, F. A. J. (2008). Autonomia e a prática micropolítica em um abrigo. Anais do I Congresso Internacional Atividades e Afetos (pp. 1-14), Belo Horizonte.

\section{Notas}

${ }^{1}$ Estas entrevistas foram realizadas no interior da pesquisa Conjugalidade, parentalidade e trabalho na juventude: desafio de uma conjugação, financiada pelo CNPq.

${ }^{2}$ Todos os nomes são fictícios e foram escolhidos por elas na época das entrevistas.

${ }^{3}$ Embora o nome atual seja instituição de acolhimento institucional, vamos utilizar a palavra abrigo no texto, de forma livre.

Recebido em 05 de janeiro de 2012 Aceito para publicação em 02 de abril de 2012 